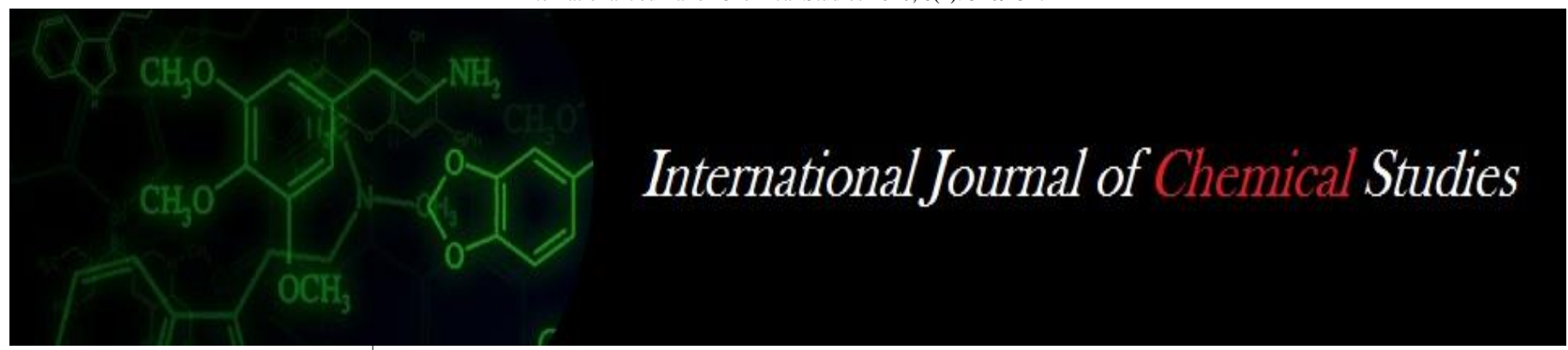

P-ISSN: 2349-8528

E-ISSN: 2321-4902

www.chemijournal.com

IJCS 2020; 8(4): 3269-3274

(C) 2020 IJCS

Received: 01-05-2020

Accepted: 03-06-2020

Subaran Singh

Department of Seed Science \&

Technology, Chaudhary Charan

Singh Haryana Agricultural

University Hisar, Haryana,

India

Supriya Ambawat

ICAR- All India Coordinated

Research Project on Pearl millet,

Agriculture University, Jodhpur,

Rajasthan, India
Corresponding Author:

Subaran Singh

Department of Seed Science \&

Technology, Chaudhary Charan

Singh Haryana Agricultural

University Hisar, Haryana,

India

\section{Microbial diversity analysis and bioremediation to evade heavy metal toxicity}

\section{Subaran Singh and Supriya Ambawat}

\author{
DOI: https://doi.org/10.22271/chemi.2020.v8.i4ao.10155
}

\begin{abstract}
Heavy metals are described based on their specific gravity carrying more than five gram per cc. Metals like iron, nickel, copper and chromium are important in very lesser concentration for continued existence of all forms of life. Most heavy metals are toxic to cells. The toxicity of heavy metal is due to their presence in abundance and buildup. Different studies related to interactions between microorganisms and heavy metals has mainly targeted on bacterial transformation and alteration of metallic ions by reduction in diverse polluted environments. Different organisms might be differentiated by observing several patterns obtained based on cleavage of their DNA using a molecular technique called Restriction Fragment Length Polymorphism (RFLP). The chromosomal G+C content is most important criteria for bacterial identification and classification based on its Tm (melting temperature) calculation. On the other hand, in silico tools like UniProtKB/Swiss-Prot and UniProtKB/TrEMBL databases can be used for pattern analysis of proteins expressed under heavy metal stresses.
\end{abstract}

Keywords: Bioremediation, heavy metals, microbes, microbial diversity, proteomics

\section{Introduction}

Soil is the main basis for plant and animal productivity which ultimately is helpful for survival and development of human being. Metals are considered as main constituent of the earth's crust from its time of creation and the early life has evolved in their presence in abundance. Thus, all living systems have evolved using some metals as essential constituents on one hand and existed with the toxic metals as well on the other hand. The primary source of metals in all ecosystems is the underlying bedrock of planet Considerable variation in metal content at the surface can result from three major sources: differences in underlying bedrock, i.e. concentration of ores, the atmosphere (mainly from volcanoes and forest fires) as well as pollution resulting due to human activities and the biosphere, resulting either from bioaccumulation or leaching of metals from soils (Wang et al., 2011) ${ }^{[26]}$. Though many metals are essential, all metal ions are toxic at a certain level. Due to high atomic mass of heavy metal cations, they can strongly bind to sulphide groups. Thus, a significant intracellular concentration of these metals and essential balance is required to avoid either metal deprivation or metal toxicity and cells must quickly eliminate them to maintain homeostasis and the elimination of purely toxic metals is simple.

With the increasing industrialization, mining and distribution of minerals from their natural deposits has increased across the world and the toxic effect of heavy metal is enhanced when mined ores are dumped in manual dressing processes. After extraction, these minerals including metals as well as heavy metals go through various technical processes of chemical changes leading to dispersion in solutions by means of dumps, effluent, sewage and dust into earth, air, water and thus ultimately enter into food chain. Increased concentrations of toxic metals have been reported to present in increased concentration in soils due to waste water sewage sludge (Sharma and Dhaliwal, 2019) ${ }^{[25]}$. Plants as well as animals take up small quantity of toxic heavy metal compounds along with essential nutrients and can concentrate them. Various heavy metals such as mercury, lead and cadmium have been found to be potentially toxic within specific limiting values thus posing a substantial potential hazard for human nutrition. However, all traces of heavy metals found in in plants and animals are not the consequences of human activities rather they may be due to absorption processes of naturally occurring soil components like cadmium. Thus, it is difficult to find the actual reason for 
increased heavy metal content. It has been estimated that every $1000 \mathrm{~kg}$ of "normal" soil has $200 \mathrm{~g}$ chromium, $80 \mathrm{~g}$ nickel, $16 \mathrm{~g}$ lead, $0.5 \mathrm{~g}$ mercury and $0.2 \mathrm{~g}$ cadmium (Collins and Stotzky, 1992) ${ }^{[6]}$. Although, these are termed as essential trace elements but when they are present in higher quantities can lead to detrimental effects. Here, boundary between the essential and toxic effect is somewhat problematic and it needs clear demarcation so that remedy for heavy metal toxicity can be taken effectively.

Bacteria are the oldest among all the life forms on earth and inhabit the greatest diversity of habitats, form a major proportion of the earth's global biomass and have the greatest capacity to absorb metals from the solution. Thus, they provide the ideal system to study the metal-microbe interactions. Like all other living organisms microbial communities adapt themselves to the metal concentrations encountered and protect themselves against metal toxicity by avoidance and sequestration strategies. Those metals are termed as "heavy metals" which have specific gravity (density) of more than about $5 \mathrm{~g} / \mathrm{cm}^{3}$ in their standard state. Many heavy metal ions have higher affinity for soft donor atoms such as phosphorus and sulfur in comparison to hard donor atoms such as nitrogen and oxygen and are termed as "soft" Lewis acids. $\mathrm{Hg}^{2+}, \mathrm{Pb}^{2+}, \mathrm{Cd}^{2+}, \mathrm{Cu}^{2+}, \mathrm{Ag}^{+}, \mathrm{Au}^{3+}, \mathrm{Pt}^{4+}$ and $\mathrm{Tl}^{+}$are among some of the soft metal ions (Wuana and Okieimen, 2011) ${ }^{[27]}$. Many soft metal ions are highly toxic and are a matter of great concern because they are present in a variety of waste streams which can contaminate the environment up to a great extent if released. Thus, a very efficient, safe and cost effective strategy for isolation and recovery of these toxic metals is required in modern day environmental scenario. Nowadays, in situ immobilization of metals, phytoremediation and biological techniques turned out to be best solution for elimination of metals from the soil. Integrated processes are gaining popularity as it is reported to achieve the goal effectively in various environmental matrices and will overcome a major drawback of large scale implementation. Several individual treatments, namely, physical, chemical, and biological are being implied to remove heavy metals from the environment (Selvi et al., 2019) [24]. Xu et al. (2019) [29] reported the design and demonstration of a remediation method based on a concept of asymmetrical alternating current electrochemistry that achieves high degrees of contaminant removal for different heavy metals (copper, lead, cadmium). Exposure of bacteria to cadmium induces expression of numerous genes related to metal transport, heat shock response, oxidative stress response and DNA repair (Dhaliwal et al., 2020) ${ }^{[9]}$.Thus, understanding the response of soil bacteria, which constitute a major biomass component in the soil, towards toxic metals is of utmost importance in environmental interest.

An inherent problem in bioremediation of toxic wastes is that the heavy metal contamination in the environment over a period of time leads to reaction with organic moieties. Lead, cadmium, mercury, zinc, copper and nickel are the most hazardous and are included on the US Environmental Protection Agency's (EPA) list of priority pollutants (Table 1). Toxic heavy metals like $\mathrm{Cd}, \mathrm{As}, \mathrm{Fe}, \mathrm{Cr}, \mathrm{Zn}, \mathrm{Cu}, \mathrm{Mn}, \mathrm{Pb}$, $\mathrm{Ni}$, etc. have been found to present in significant concentration in soil, surface, and ground water have been reported in various countries like China, Italy, Germany, Hong Kong, India, Turkey, Bangladesh, Greece, Iran etc. (Kaonga et al., 2017) ${ }^{[15]}$. Cadmium is a non-essential, widely spread, highly toxic, human carcinogen leading to high environmental risk. The extreme use of phosphatic fertilizers, sewage sludge dispersal and atmospheric deposition causes severe contamination of agricultural soils by $\mathrm{Cd}$. Its absorption occurs because of the chemical similarity to zinc and it is readily taken up by several crops like cereals, potatoes, fruits and vegetables leading to its increased level of contamination in human food as well as agricultural field.

Table 1: Classification of heavy metals with examples

\begin{tabular}{|c|c|}
\hline Classification of heavy metals & Significant examples \\
\hline Micro-nutrient elements & Copper, Nickel, Chromium, Iron, Manganese, Molybdenum \\
\hline Macro-nutrient elements & Cobalt, Iron \\
\hline Highly toxic elements & Mercury Cadmium, Lead, Silver, Gold, Palladium, Bismuth, Arsenic, Platinum, Selenium, Tin, Zinc \\
\hline Radio nuclides & Uranium, Thorium, Radium, Cerium, Praseodymium \\
\hline Precious elements & Platinum, Silver, Gold, Palladium, Ruthenium \\
\hline
\end{tabular}

Generally, the cations and anions formed from the metals are toxic rather than the reduced metallic material. The toxicity of heavy metals is due to their presence in abundance while their non-biodegradable nature is responsible for their concentration build up. Some microorganisms are known to resist the higher concentration of heavy metals and thus, help in removing these from contaminated sites. Sporosarcina ginsengisoli, Candida glabrata, Bacillus cereus, and Aspergillus niger are some of the microbes used in immobilization technique to remove heavy metals (Littera et al., 2011; Giri et al., 2012) ${ }^{[18,12]}$. Remediation mechanism includes extracellular complexation, intracellular accumulation, and precipitation or oxidation-reduction process. Microbial leaching is simple and effective for extracting metals from low-grade minerals. Induction of oxidative stress and interference in protein folding and functioning are some of the known mechanisms of heavy metal toxicity (Lianwen et al., 2018) ${ }^{[17]}$. The ability of microorganisms to survive and reproduce in a metals habitat may depend on genetic as well as physiological adaptations. The former leads to the wide spread appearance of metal resistant organisms. Heavy metal resistance mechanism and its genetic basis differ with microbe and the metal in question. A natural isolate from contaminated habitat will be an ideal candidate to work on heavy metal resistance mechanism.

Bioremediation may be defined as the use of microorganism and plants for decontamination of heavy metals. It is very useful strategy and drawing attention due to its high efficiency. Microorganisms can be helpful in this process as they can either remove the metals from polluted soils and sediments or solubilize metals thus facilitating their easy extraction. Further, they can absorb and concentrate heavy metals and ultimately provide resistance. Indigenous microorganisms may prove more useful because they are already adapted to prerequisite survival conditions in the contaminated soil. Bacteria possess several resistance mechanisms to counteract heavy metals stresses including formation and sequestration of heavy metals complexes, reduction of metals to a less toxic species and direct efflux of metal out of cell (Galal et al., 2017) ${ }^{[11]}$. Microbial methods of 
environmental refinement are most promising because of their efficiency, safety and cost-effectiveness.

\section{Heavy metal toxicity}

Most heavy metal ions can cause any physiological toxic effect only after entering the cell. Divalent heavy metal cations have structural similarity to the divalent cations like $\mathrm{Mn}^{2+}, \mathrm{Fe}^{2+}, \mathrm{Co}^{2+}, \mathrm{Ni}^{2+}, \mathrm{Cu}^{2+}$ and $\mathrm{Zn}^{2+}$ with ionic diameters in a range of 138-160 pm. They are mostly double-positively charged except oxyanions like chromate which are doublenegatively charged with four tetrahedrally arranged oxygen atom and vary primarily in size of the central ion thus resembling structure of sulphate. Similarly, arsenate resembles phosphate and thus uptake systems for heavy metal ions have must be very efficient to bind those ions tightly so as to differentiate them from the structurally very similar ions. Thus, toxic metal cations may be removed by substituting them with essential cations with the help of the enzymes $e . g$., $\mathrm{Cd}^{2+}$ could be replace with $\mathrm{Zn}^{2+}$ (Sandrin and Maier, 2003) ${ }^{[23]}$. Cadmium is a very rare element in the Earth's crust $(0.00002 \%)$ and occurs mainly as the sulphide or carbonate in zinc ores. It belongs to d-block, as a transitional element in the periodic table. It shares closely related properties of toxicity with $\mathrm{Zn}$ and $\mathrm{Hg}$. Cadmium exists in natural abundance in the earth's crust with an average of 0.1 to 0.5 $\mathrm{mg} / \mathrm{g}$ though much higher and much lower values are also found due to several factors. Sedimentary rocks exhibit much higher values ranging from 0.1 to $25 \mathrm{mg} / \mathrm{g}$ while igneous and metamorphic rocks contain lower values, from 0.02 to 0.2 $\mathrm{mg} / \mathrm{g}$. Sulphide sand oxides of zinc, lead and copper contain even higher levels- 200-14,000 mg/g for zinc ores and about $500 \mathrm{mg} / \mathrm{g}$ for lead and copper ores (Cook and Morrow, 1995) [7]. Cadmium can exist in surface and groundwater water in various forms such as hydrated ion, inorganic complexes of hydroxides, sulphates, carbonates or chlorides or as organic complexes with humic acids. The average cadmium contents of fresh waters, rainwater and surface waters were found to vary upto a larger extent in urban and industrialized areas. It varied from 10-4000 ng/l depending on the specific location and whether cadmium is dissolved or undissolved. Cadmium ions generally accumulates up the trophic levels because very few living organisms have evolved methods for regulating these ions and compounds of cadmium have little or no biological role in comparison to zinc. Heavy metal ions and metalloids can prove to be very toxic to cells as they can bind to essential respiratory chain proteins or may lead to oxidation damage (Canovas et al., 2003) ${ }^{[4]}$. Heavy metals block the transport of potassium and sugars into cells by binding to the $\mathrm{S}-\mathrm{H}$ groups on the cell membrane and after entering inside the cell, it may be sequestered as an inactive combination, or it may react with enzymes or other compounds to elicit toxic effects.

\section{Metal resistance mechanisms}

The different studies for interactions between heavy metals and microorganisms have mainly focused towards bacterial transformation and conversion of metallic ions using reduction process in different polluted environments and it has been observed that heavy metal ions react to form toxic compounds in cells at high concentrations. Metal-resistant microorganisms can be selected and isolated from polluted environments and can be used as indicators of potential toxicity to other forms of life and different mechanisms, determinants and genetic transfer of microbial metalresistance has been reported by Olson and Thornton (1982)
[20]. Several uptake mechanisms subsist to allow entrance of metal ions into the cell because some of the heavy metals are essential for enzymatic functions and bacterial growth. Generally, two uptake systems exists - first is an unspecific, more energy efficient and quick method determined by a chemiosmotic gradient across the cell membrane with no requirement of ATP, while another one is more substratespecific, slower and driven by energy from ATP hydrolysis (Anne, 2003) ${ }^{[1]}$. A wide variety of heavy metals can enter due to first mechanism and when such metals exist in higher concentrations they can have toxic effects inside the cell. Cadmium resistance in gram positive bacteria was found to be mediated by Cad A like protein and CadA pump was the first cadmium exporting heavy metal P-type ATPase isolated from gram negative bacteria Staphylococcus aureus. Later, it was found that all the copper, lead and zinc transporters are related to this protein and $\mathrm{CadA}$ is induced by $\mathrm{Cd}, \mathrm{Zn}$ and $\mathrm{Pb}$ (Huan et al., 2017) ${ }^{[13]}$. On the other hand, in gram negative bacteria, cadmium is detoxified by RND (resistance, nodulation, cell division) driven system like CZC, which is mainly a zinc exporter. Cad R belong to the mer family of transcriptional regulators in Pseudomanas putida 06909, and it responds to $\mathrm{Cd}$ and represses its own expression, but is not required for the regulation.

\section{Microbial diversity analysis}

A huge amount of diversity of microbes exists in nature but mainly it remains unexplored. However, in environments contaminated with heavy metals in addition to organic pollutants, species diversity and metabolic activities of the microorganisms are reduced and metal-tolerant bacterial populations predominated by Pseudomonas and/or acidophilic bacteria develop (Dopson et al., 2003) ${ }^{[10]}$. Various methods and novel strategies based on rRNA and rDNA analyses have been used to discover and explore the microbial diversity. In the era of microbial ecology, a major step towards retrieving of genomic, evolutionary and functional information from bacterial artificial chromosome libraries of the soil community genomes can prove to be very useful. Molecular phylogenetics, DNA microarrays, functional genomics and in situ activity measurements are some of the strategies which can generate enormous data and can prove useful in understanding the structure and function of microbial ecosystems and the various interactions occurring between them. Subsequently, with the use of such novel methods and approaches functional diversity and relationships existing among microbial communities may be explored upto a large extent and can be exploited for bioremediation process.

Several methods have been used for microbial diversity analysis which involves a combination of microscopy and nucleic acid characterization. Different biochemical and molecular methods can be used to identify and characterize several bacterial communities isolated from polluted environment and ultimately may be used for heavy metal removal by bioremediation processes using cadmium-resistant bacterial strains. Among the molecular methods, 16S rRNA gene sequencing has turned out to be very useful for identification of unknown bacteria. Thus, total community DNA extracted from the environment may be used to perform broad-scale community analysis using DNA re-association technique revealing the total genetic diversity of a given bacterial community (Derakshani et al., 2001) ${ }^{[8]}$. On the other hand, changes in microbial community structure can be detected by shift in guanine + cytosine $(\mathrm{G}+\mathrm{C})$ content but it can't be used to get any information about the other diversity 
parameters like richness, evenness and composition. In addition, Polymerase Chain reaction (PCR) based fingerprinting technique can be useful for higher resolution as well as provides information about whole community structural changes. Information on the species composition and comparative studies among the common species present in sample can be done by several fingerprinting techniques like phospholipid fatty acid (PLFA) analysis, amplified rDNA restriction analysis (ARDRA), denaturant gradient gel electrophoresis (DGGE), ribosomal intergenic spacer analysis (RISA) and terminal restriction fragment length polymorphism (T-RFLP). They can remove cadmium from solution in the similar way as cadmium resistant bacterial isolates do and the efficiency of cadmium removal is correlated with the amount of additionally synthesized proteins in the cell fractions. The different techniques mainly used for diversification study among microbes are described below:

\section{Restriction Fragment Length Polymorphism (RFLP)}

Various organisms may be differentiated by analysis of patterns derived from cleavage of their DNA using RFLP technique. Each organism inherits its DNA from its parents and when DNA is replicated with each generation, any given sequence can be passed on to the next generation forming the basis of analysis of detection of variations in fragments. An RFLP is a sequence of DNA that has a restriction site on each end with a "target" sequence in between (Barkay et al., 1985) [2]. Upon digestion of DNA with a restriction enzyme, different fragments are generated of varying length resulting into a different pattern in various organisms due to difference in the distance between sites of cleavage of a particular restriction endonuclease which can be ultimately used to differentiate species/strains from one another based on RFLP technique.

\section{Polymerase Chain Reaction (PCR)}

A specific region of DNA can be amplified using this technique by a set of primers and a thermostable DNA polymerase. Millions of copies of a specific piece of DNA molecule ranging between 150-3,000 base pairs in length can be obtained and the PCR product can be analyzed by gel electrophoresis. Thus, PCR and DNA sequences analysis evidences can provide information regarding loci those confer resistance to metals present within the diverse group of microbial community with amplified conserved region among them (Wuertz and Mergeay, 1997) ${ }^{[28]}$.

\section{G+C Determination by Melting Temperature (Tm)}

$\mathrm{G}+\mathrm{C}$ content of a bacterial chromosome is an important index and can be used for identification and classification of bacteria by calculating its Tm (melting temperature). The $\mathrm{G}+\mathrm{C}$ content varies from 25 to $80 \mathrm{~mol} \%$ for bacterial chromosomal DNA and various methods have been used to determine this value. The most common technique for determination of bacterial DNA $\mathrm{G}+\mathrm{C}$ content is thermal denaturation temperature $(\mathrm{Tm})$ in which the increase of absorbance at $260 \mathrm{~nm}$ during DNA denaturation is measured. Another simple and rapid method involves determination of Tm by Thermal Light Cycler and calculation of the $\mathrm{G}+\mathrm{C}$ content by an empirical formula: mol\% $\mathrm{G}+\mathrm{C} x=\mathrm{mol} \%$ $\mathrm{G}+\mathrm{C} r+1.99\left(T \mathrm{~m}_{x}-T \mathrm{~m}_{r}\right)$ (where $x$ is the unknown organism and $r$ is the reference organism) relating $\mathrm{Tm}$ to $\mathrm{G}+\mathrm{C}$ content (Mandel et al., 1970). Staphylococcus aureus has ATCC $12600^{\mathrm{T}}$ for low $\mathrm{G}+\mathrm{C}$ contents, Escherichia coli ATCC $11775^{\mathrm{T}}$ for medium $\mathrm{G}+\mathrm{C}$ contents and $P$. aeruginosa ATCC $10145^{\mathrm{T}}$ for high $\mathrm{G}+\mathrm{C}$ content depicting the diversity of microorganisms from each other (Mesbah et al., 1989) ${ }^{[19]}$.

\section{Evolutionary Relationship}

CadR is a cadmium-induced regulator of $c a d A$ transporter and both of these determine cadmium and zinc resistance as cadR and $c a d A$ form a divergent. Only the transporter gene $c a d A$ has a typical promoter in a correct position relative to the CadR-binding palindrome, while the regulator gene itself is either not regulated or only repressed. The $p b r R$ locus consists of six genes encoding the $\mathrm{Pb}[\mathrm{II}]$ uptake protein $\mathrm{PbrT}$, the $\mathrm{P}$ type $\mathrm{Pb}[\mathrm{II}]$, efflux ATPase PbrA, predicted integral protein $\mathrm{PbrB}$, predicted signal peptidase $\mathrm{PbrC}$ and $\mathrm{Pb}$ [II] binding protein $\mathrm{PbrD}$ as determined in the Cupriavidus metallidurans plasmid pMOL30 (Chen et al., 2005) ${ }^{[5]}$. PbrR is regulator of lead resistance in $C$. metalliduran and inspite of different regulon context and transporter specificity, CadR and PbrR regulators form one branch of the phylogenetic tree. The cadmium transporters belong to the P-type ATPase (PATPase) superfamily [TC \#3.A.3 in the Transporter Classification Database, (http://tcdb.ucsd.edu.) like other identified transporters for zinc, lead and copper and form divergons with their regulators like zinc transporters.

All the members of P-type ATPase family catalyze cation uptake and/or efflux driven by ATP hydrolysis and some effluxers have the eight transmembrane segment topology. All identified cadmium loci from P-ATPase superfamily are located on the chromosome including divergently arranged transporters and regulators except $C$. metallidurans, where it is located on a mega plasmid and the locus is formed by the convergently transcribed regulator and transporter (only the transporter gene has a potential site). The divergently arranged transporter is not homologous to CadA but belongs to Cation Diffusion Facilitator (CDF) family when the regulator lies on a plasmid (two cases on plasmid pWW0 in Pseudomonas putida (AAN60471, CAC86841) and one on pKLH202 in Acinetobacter lwoffii (CAD31090). These transporters are annotated as putative membrane transport proteins or cation efflux system proteins while some of their homologs are annotated as $\mathrm{Co} / \mathrm{Zn} / \mathrm{Cd}$ efflux system components (Brocklehurst et al., 2003) ${ }^{[3]}$.

\section{Proteomics and 2D Gel}

With the publication of the complete genomes of organisms, a new scientific discipline, proteomics has arisen. With comparative studies of protein composition (the proteome) of microorganisms and the contribution of differentially expressed proteins/genes for specific microbial trait has been assessed. The proteomic study has been made with 2D-gel electrophoresis analysis and proteins of interest can be identified on the genome by MALDI-TOF MS (mass spectroscopy). 2D gel analysis study provides comparative functional diversity among heavy metal resistant microorganisms (Rani et al., 2009) ${ }^{[21]}$. It separates proteins first on their isoelectric point and in the second dimension on their molecular mass. The proteins are separated by electrophoresis on $12 \%$ SDS-polyacrylamide gels and staining is being done with silver. Proteome characterization of various proteins involved in heavy metal resistance was reported (Jain et al., 2010) ${ }^{[14]}$. 2D gel combines fast visual identification, spot matching and insilico analysis tool for sorting, filtering and annotating spot data. Statistical analysis became most reliable, since we can easily achieve full expression profiles without missing values using $100 \%$ spot matching approach. The 
ExPASy (Expert Protein Analysis System) proteomics server of the Swiss Institute of Bioinformatics (SIB) is mainly used to analyze the protein structures, sequence and 2-D PAGE.

\section{Role of Bioinformatics}

Functional characterization of diversity among bacterial isolates can be done by in silico analysis of metal binding proteins and identification of putative metal binding motifs for the ions of cadmium, cobalt, zinc, arsenic, mercury, magnesium, manganese, molybdenum and nickel. Proteins mediating transport, buffering or detoxification of metal ions have metal ion binding domains. Richard et al. (2007) [22] performed an in silico analysis of metal binding proteins and identified putative metal binding motifs for the ions of cadmium, cobalt, zinc, arsenic, mercury, magnesium, manganese, molybdenum and nickel and these motifs were also validated against PDB structures. True positives were observed after performing a pattern search against the UniProtKB/Swiss-Prot and UniProtKB/TrEMBL databases revealing the high-specificity of the motifs. Leedjarv et al. (2008) [16] described the different roles of distinct, but simultaneously functioning transporters. Upon in silico analysis, it was observed that four $\mathrm{Zn} / \mathrm{Cd} / \mathrm{Pb}$ efflux transporters - two P-type ATPases, CadA1 and CadA2 and two Czc chemiosmotic transporters, CzcCBA1 and CzcCBA2 exist in the genome of Pseudomonas putida KT2440 and all the transporters are functional but under laboratory conditions only two of them were involved in the mediation of heavy metal resistance in $P$. putida KT2440. CadA2 was found to be associated with $\mathrm{Cd}^{2+}$ and $\mathrm{Pb}^{2+}$ resistance while CzcCBA1 conferred export of $\mathrm{Zn}^{2+}, \mathrm{Cd}^{2+}$ and $\mathrm{Pb}^{2+}$. CadA1 was found to be nonfunctional in $P$. putida but it enhanced $\mathrm{Zn}^{2+}$ resistance and slightly $\mathrm{Cd}^{2+}$ resistance when expressed in Escherichia coli. CzcCBA2 was found to be associated with $\mathrm{Zn}$ resistance of a czcA1-defective $P$. putida strain during the overexpression of $\mathrm{CzcA} 2$ subunit in transporter-deficient strain. Thus, it indicated that $\mathrm{CzcA} 2$ can complement the loss of $\mathrm{CzcA} 1$ by complexing with $\mathrm{CzcC} 1$ and $\mathrm{CzcB} 1$ subunits when $\mathrm{CzcCBA} 2$ transporter becomes nonfunctional. It was also revealed that heavy metals induce expression of cadA1, cadA2 and czcCBA1 while growth medium and growth phase determine the expression levels. $\mathrm{Zn}^{2+}, \mathrm{Cd}^{2+}, \mathrm{Pb}^{2+}, \mathrm{Ni}^{2+}, \mathrm{Co}^{2+}$ and $\mathrm{Hg}^{2+}$ induced both cadA2 and czcCBA1 and their expression was found to be non-specific while only $\mathrm{Zn}^{2+}$ induced expression of cadA1.

\section{Conclusion}

Heavy metal is a serious problem in the earth crust and in pollutants released by industry as effluents. Microbes play important roles to remove these heavy metals with their interaction either via conversion or reduction in the non toxicable form. The molecular techniques proved useful in revealing diversity among heavy metal resistant microbes. The pattern analysis of microbes and proteomic study can be done using in silico data base. The comparative analysis of proteins expressed under heavy metal stress in microbes can be identified and this proteomic analysis may be useful to identify the microbes performing better under heavy metal stress. Based on these interpretations we can find microbes for bioremediation for different problematic soils and crops.

\section{Acknowledgements}

We sincerely acknowledge DBT, Govt. of India for providing scholarship to SS.
Conflict of Interest: The authors declare that they have no competing interest.

\section{References}

1. Anne S. Implications of Microbial Heavy Metal Tolerance in the Environment. Review in Undergraduate Res. 2003; 2:1-6.

2. Barkay T, Tripp SC, Olson BH. Effect of metal rich sewage sludge application on the communities of grassland. Appl. Environ. Microbio. 1985; 49:333-337.

3. Brocklehurst KR, Megit SJ, Morby AP. Characterisation of CadR from Pseudomonas aeruginosa: a Cd (II)responsive MerRhomologue. Biochem Biophys Res Commun. 2003; 308(2):234-239.

4. Canovas D, Cases I, DeLorenzo V. Heavy metal tolerance and metal homeostasis in Pseudomonas putida as revealed by complete genome analysis. Environ. Microbiol. 2003; 5(12):1242-1256.

5. Chen P, Greenberg B, Taghavi S, Romano C, Lelie DVD, He C et al. An Exceptionally Selective Lead (ii)Regulatory Protein from Ralstonia metallidurans: Development of a Fluorescent Lead (ii) Probe. Angew Chem Int Ed. 2005; 44:2-6.

6. Collins YE, Stotzky G. Heavy metals alter the electrokinetic properties of bacteria, yeasts, and clay minerals. Appl Environ Microbiol. 1992; 58:1592-1600.

7. Cook ME, Morrow H. Anthropogenic Sources of Cadmium in Canada" National Workshop on Cadmium Transport into Plants, Canadian Network of Toxicology Centres, Ottawa, Ontario, Canada, June 20-21, 1995.

8. Derakshani M, Lukow T, Liesack W. Novel bacterial lineages at the (sub) division level as detected by signature nucleotide-targeted recovery of $16 \mathrm{~S}$ rRNA genes from bulk soil and rice roots of flooded rice microcosms. Appl Environ Microbiol. 2001; 67:623-631.

9. Dhaliwal SS, Singh J, Taneja PK, Mandal A. Remediation techniques for removal of heavy metals from the soil contaminated through different sources: a review. Environmental Science and Pollution Research. 2020; 27:1319-1333.

10. Dopson M, Baker-Austin C, Koppineedi PR, Bond PL. Growth in sulfidic mineral environments: metal resistance mechanisms in acidophilic micro-organisms. Microbiology. 2003; 149:1959-1970.

11. Galal TM, Gharib FA, Ghazi SM, Mansour KH. Phytostabilization of heavy metals by the emergent macrophyte Vossia cuspidate (Roxb.) Griff. a phytoremediation approach. Int J Phytoremed. 2017; 19:992-999.

12. Giri AK, Patel RK, Mishra PC. Biosorption of As (V) from aqueous solutions by living cells of Bacillus cereus. Water Sci. Technol. 2012; 66:699-707.

13. Huan L, Haixia Z, Longhua W, Anna L, Fang-Jie Z, Wenzhong $\mathrm{X}$ et al. Heavy metal ATPase 3 (HMA3) confers cadmium hypertolerance on the cadmium/zinc hyperaccumulator Sedum plumbizincicola. New Phytol. 2017; 15:687-698.

14. Jain S, Rani A, Marla SS, Goel R. Differential proteomic analysis of psychrotolerant Pseudomonas putida 710Aand alkaliphilic Pseudomonas monteilli 97AN for cadmium stress. Int J Biol Med Res. 2010; 1(4):234-241.

15. Kaonga CC, Kosamu IB, Lakudzala DD, Mbewe R, Thole B, Monjerezi M et al. A review of heavy metals in soil and aquatic systems of urban and semi-urban areas in 
Malawi with comparisons to other selected countries. Afr. J Environ. Sci. Technol. 2017; 11:448-460.

16. Leedjarv A, Angela I, Marko V. Interplay of different transporters in the mediation of divalent heavy metal resistance in Pseudomonas putida KT2440-J Bacteriol. 2008; 190:2680-2689.

17. Lianwen L, Wei L, Weiping S, Mingxin G. Remediation techniques for heavy metal-contaminated soils: principles and applicability. Sci Total Environ. 2018; 633:206-219.

18. Littera P, Urík M, Sevc J, Kolencík M, Gardosová K, Molnárová, $\mathrm{M}$ et al. Removal of arsenic from aqueous environments by native and chemically modified biomass of Aspergillus niger and Neosartorya fischeri. Environ. Technol. 2011; 32:1215-1222.

19. Mesbah M, Premachandran U, Whitman WB. Precise measurement of the $\mathrm{G}+\mathrm{C}$ content of deoxyribonucleic acid by high-performance liquid chromatography. Int $\mathbf{J}$ Syst Bacteriol. 1989; 39:159-167.

20. Olson BH, Thornton I. The resistance pattern to metals of bacterial population in contaminates land. J. Soil. Sci. 1982; 33:273-277.

21. Rani A, Souche YS, Goel R. Comparative assessment of in situ bioremediation potential of cadmium resistant acidophilic Pseudomonas putida $62 \quad \mathrm{BN}$ and alkalophilic Pseudomonas monteilli 97AN strains on soybean. Internl Biodeterioration and Biodegradation. 2009; 63(1):62-66.

22. Richard T, Krishnan R, Sharmila A, Gautam P. In silico identification of putative metal binding motifs. Bioinformatics. 2007; 23(3):267-271.

23. Sandrin TR, Maier RM. Impact of Metals on the biodegradation of organic pollutants. Environmental Health Perspectives. 2003; 111:1093-1101.

24. Selvi A, Rajasekar A, Theerthagiri J, Ananthaselvam A, Sathishkumar K, Madhavan $\mathrm{J}$ et al. Integrated Remediation Processes Toward Heavy MetalRemoval/Recovery From Various Environments-A Review. Front. Environ. Sci. 2019; 7:66.

25. Sharma S, Dhaliwal SS. Effect of sewage sludge and rice straw compost on yield, micronutrient availability and soil quality under rice-wheat system. Commun Soil Sci Plant Anal. 2019; 50:1943-1954.

26. Wang B, Liu GB, Xue S, Zhu B. Changes in soil physicochemical and microbiological properties during natural succession on abandoned farmland in the loess plateau. Environ Earth Sci. 2011; 62:915-925.

27. Wuana RA, Okieimen FE. Heavy metals in contaminated soils: a review of sources, chemistry, risks and best available strategies for remediation. ISRN Ecol. 2011; 402647:20. doi: 10.5402/2011/402647.

28. Wuertz S, Mergeay M. The impact of heavy metals on soil microbial communities and their activities. Modern Soil Microbiology, Marcel Decker, NY, 1997, 1-20.

29. Xu J, Liu C, Hsu PC, Zhao J, Wu T, Tang J et al. Remediation of heavy metal contaminated soil by asymmetrical alternating current electrochemistry. Nature Communications. 2019; 10:2440. 